\title{
Study Subject Ultrasound Report
}

National Cancer Institute

\section{Source}

National Cancer Institute. Study Subject Ultrasound Report. NCI Thesaurus. Code

C115515.

Records pertaining to the findings from a study subject's ultrasound images. 